\title{
Development of Decision Support Model for Selecting a Maintenance Plan Using a Fuzzy MCDM Approach: A Theoretical Framework
}

\author{
Fathia Sghayer Abdulgader, ${ }^{1}$ Rajeh Eid, ${ }^{1}$ \\ and Babak Daneshvar Rouyendegh (B. Erdebilli) (iD) ${ }^{2}$ \\ ${ }^{1}$ Attlim University, 06836, Incek, Ankara, Turkey \\ ${ }^{2}$ Department of Industrial Engineering, Ankara Yıldırım Beyazıt University, 06010 Ankara, Turkey \\ Correspondence should be addressed to Babak Daneshvar Rouyendegh (B. Erdebilli); babek.erdebilli2015@gmail.com
}

Received 10 May 2018; Revised 5 September 2018; Accepted 27 September 2018; Published 1 November 2018

Academic Editor: Samuel Huang

Copyright (C) 2018 Fathia Sghayer Abdulgader et al. This is an open access article distributed under the Creative Commons Attribution License, which permits unrestricted use, distribution, and reproduction in any medium, provided the original work is properly cited.

\begin{abstract}
In complex decision making, using multicriteria decision-making (MCDM) methodologies is the most scientific way to ensure an informed and justified decision between several alternatives. MCDMs have been used in different ways and with several applications that proved their efficiency in achieving this goal. In this research, the advantages and disadvantages of the different MCDM methodologies are studied, along with the different techniques implemented to increase their accuracy and precision. The main aim of the study is to develop a hybrid MCDM process that combines the strengths of several MCDM methods and apply it to choose the best fit maintenance policy/strategy for industrial application. Moreover, fuzzy linguistic terms are utilized in all of the used MCDM techniques in order to eliminate the uncertainty and ambiguity of the results. Through an extensive literature review performed on studies that have used MCDM methods in a hybrid context and using fuzzy linguistic terms, a model is developed to use fuzzy DEMATEL-AHP-TOPSIS hybrid technique. The model with its application is the first of its kind, which combines the strengths of fuzzy DEMATEL in establishing interrelationships between several criteria, as well as performing a pairwise comparison between the criteria for prioritization using the fuzzy AHP method. Thereafter, the alternatives are compared using fuzzy TOPSIS method by establishing negative and positive solutions and calculating the relative closeness for each of the alternatives. Furthermore, six main criteria, twenty criteria, and five alternatives are selected from the literature for the model application.
\end{abstract}

\section{Introduction}

Multiple criteria decision making $(\mathrm{MCDM})$ is a procedure that permits to settle on choices within the sight of various, typically clashing, criteria. The issues of MCDM can be comprehensively grouped into two classes [1]:

(1) Multiple Attribute Decision Making (MADM) includes the choice of the "best" option from preindicated options described in terms of multiple attributes.

(2) Multiple Objective Decision Making (MODM) includes the plan of choices which advance the numerous goals of the Decision Maker.
(3) The ordinary MCDM issue manages the assessment of an arrangement of options regarding an arrangement of choice criteria.

Multicriteria Decision Making is a valuable tool in numerous practical, producing, material determination, military, and constructional issues particularly assuming an essential part in fields of project choice, extended assessment, monetary advantage assessment, staff evaluation, et cetera. So far numerous methods have been proposed to solve multiple attribute decision-making problems. Multiattribute Decision Making is the investigation of recognizing and picking choices in light of the qualities and inclinations of the decision maker. Settling on a choice suggests that there are elective 
decisions to be considered and in such a case we will not just distinguish whatever number of these options as could be allowed; however, we will choose the one that best fits with our objectives, targets, qualities, etc. [1].

There are numerous ways to classify MCDM strategies. One approach is to group them as per the kind of information they utilize, according to deterministic, stochastic, or fuzzy MADM methods. However, there may be situations which involve combinations of all the above data types (such as stochastic and fuzzy data). Another way of classifying MCDM is according to the number of decision makers included in the decision process [2].

1.1. AHP. A standout among the most well-known procedures for complex decision-making issues is the analytic hierarchy process (AHP) created by Saaty (1980), which breaks down a decision-making problem into an arrangement of progressions of goals, attributes (or criteria), and options. AHP can have the same number of levels as expected to completely describe a specific decision situation. Various practical attributes make AHP a helpful system. These incorporate the capacity to deal with decision situations including subjective judgements, various decision makers, and the capacity to give measures of consistency of inclination. Intended to reflect the way individuals really think, AHP keeps on being the most exceedingly respected and broadly utilized decisionmaking strategy. AHP can effectively manage substantial (i.e., objective) and nontangible (i.e., subjective) characteristics, particularly where the subjective judgements of various people constitute an essential part of the decision process [3].

The application of the AHP to the complex problem usually involves four major steps [3]:

(1) Separate the complex issue into various little constituent components and after that structure the components in a hierarchical frame.

(2) Make a series of pairwise comparisons among the elements according to a ratio scale.

(3) Use the eigenvalue method to estimate the relative weights of the elements.

(4) Aggregate these relative weights and synthesize them for the final measurement of given decision alternatives.

The AHP technique has the following identified advantages [2]:

(1) Flexibility, instinctive interest to the decision makers, and its capacity to check irregularities: for the most part, users discover pairwise comparison type of information, direct and helpful.

(2) The AHP method supports group decision-making through consensus by calculating the geometric mean of the individual pairwise comparisons.

Nevertheless, the following disadvantages about using the AHP method can also be identified [2]:

(1) With AHP the decision issue is deteriorated into various subsystems, inside which and between which a considerable number of pairwise comparisons should be finished. This approach has the burden that the quantity of pairwise comparisons to be made may turn out to be extensive $(n(n-1) / 2)$ and in this way turn into a protracted assignment.

(2) There is the artificial limitation of the use of the 9point scale. Sometimes, the decision- maker might find it difficult to differentiate between them and tell for example whether one alternative is 6 or 7 times more important than another.

1.2. TOPSIS. This technique depends on the idea that the chosen alternative ought to have the most limited Euclidean separation from the perfect arrangement, and the most distant from the negative ideal solution. The ideal solution is a speculative answer for which all ascribed esteems relate to the maximum attribute values in the database including the satisfying solutions; the negative ideal solution is the theoretical answer for which all attribute values correspond to the minimum attribute values in the database. TOPSIS along with these lines gives an answer that is not just nearest to the theoretically best, but likewise is the most distant from the hypothetically worst [1].

The TOPSIS method is expressed in a succession of six steps as follows.

Step 1. Calculate the normalized decision matrix and the normalized value.

Step 2. Calculate the weighted normalized decision matrix.

Step 3. Determine the ideal and negative ideal solutions.

Step 4. Calculate the separation measures using the $\mathrm{m}$ dimensional Euclidean distance, the separation measures of each alternative from the positive ideal solution, and the negative ideal solution.

Step 5. Calculate the relative closeness to the ideal solution.

Step 6. Rank the preference order.

Similar to the AHP technique, TOPSIS has its advantages, which are as follows [4]:

(1) It takes contribution as any number of criteria and attributes.

(2) It has genuinely instinctive physical importance in light of the thought of separation from perfect arrangements.

Moreover, the following disadvantages are identified for TOPSIS.

(1) It is easy and can give unreliable results.

(2) TOPSIS in its standard form is deterministic and does not consider uncertainty in weightings [4].

1.3. DEMATEL. DEMATEL is based on the premise of diagram hypothesis, enabling investigations and solutions of 
issues by visualization technique. This structural modeling method embraces the type of a coordinated chart, a causal impact outline, to introduce the association connections and the values of influential impact between variables. Through examination of visual relationship of levels among framework factors, all components are isolated into causal gathering and affected gathering. And this can provide researchers with a better understanding of the structural relationship between system elements and find ways to solve complicated system problems $[5,6]$.

The relationships between cause and effect factors are converted into the DEMATEL. Suppose that a system composes a set of elements $C=\left\{c_{1}, c_{2}, c_{3}, . ., c_{n}\right\}$, and particular pairwise relations are decided for modeling with respect to a mathematical relation. The major steps are [5] as follows:

(1) Generating the direct relation matrix. Measuring the relationship between criteria requires that the comparison scale be designed into four levels:

\section{0 (no influence) \\ 1 (very low influence) \\ 2 (low influence) \\ 3 (high influence) \\ 4 (very high influence)}

An initial direct relation matrix $A$ is a $n-n$ matrix obtained by pairwise comparisons, in which $\mathrm{T}_{\mathrm{ij}}$ is denoted as the degree to which the criterion $i$ affects the criterion $j$.

(2) Normalizing the direct relation matrix. It is based on the direct relation matrix A.

(3) Attaining the total relation matrix. Once the normalized direct relation matrix $S$ is obtained, the total relation matrix I is denoted as the identity matrix.

(4) Producing a causal diagram. The sum of rows and the sum of columns are separately denoted as vectors D and $\mathrm{R}$ within the total relation matrix $\mathrm{M}$. A cause and effect graph can be acquired by mapping the dataset of (D R, D _ R). The horizontal axis vector (D R) named "Prominence" is made by adding $\mathrm{D}$ to $\mathrm{R}$, which reveals how much importance the criterion has. Similarly, the vertical axis ( $D_{-} \mathrm{R}$ ) named "Relation" is made by subtracting $\mathrm{D}$ from $\mathrm{R}$, which may group criteria into a cause group. Or, if the $\left(D_{-} R\right)$ is negative, the criterion is grouped into the effect group.

(5) Obtaining the inner dependence matrix. In this step, the sum of each column in total relation matrix is equal to 1 by the normalization method, and then the inner dependence matrix can be acquired [7].

\section{MCDM Equipment Maintenance Application}

There are several applications, where MCDM methods were used in the literature for equipment maintenance strategy selection, empowerment, or optimization. Muinde et al. (2014) identified five main types of maintenance strategies, which are passive, reactive, preventive, predictive, and proactive. In this study, the authors used the AHP method to select the most suitable strategy for the case study of a cement factory in Kenya by preforming twenty interviews with the maintenance staff, who provided their evaluation on the pairwise comparison questionnaire between the different criteria. Moreover, the study used factor analysis in order to group the different factors into criteria based on their interdependency [8].

Subsequently, the authors highlight that more than one decision maker has been sought in order to ensure consensus among the maintenance department members. In the results of the study, the criteria of the study were evaluated and assigned to scores against the alternative, where the highest score was found for proactive maintenance $(54.58 \%)$, followed by preventive $(22.94 \%)$, predictive $(22.65 \%)$, and reactive (10.23\%). Figure 1 shows the AHP model along with the scores of the criteria and alternatives [8].

A similar methodology is used by Karthik et al. (2017), where the AHP method is suggested. The main aim of the research is to optimize an existing maintenance strategy, rather than choosing between alternatives. The model suggested starts by simulating the process on a Project Evaluation and Review Technique (PERT) network and running simulation. Thereafter, the process continues by the implementation of the AHP method. In the study the main criteria for comparison are suggested as the following [9]:

(1) Equipment reliability

(2) Equipment availability

(3) Equipment maintainability

(4) Environment and personnel safety

(5) Maintenance cost

(6) Mean time between failure

Furthermore, another study suggested AHP for equipment maintenance strategy selection. The authors emphasized the importance of maintenance in the manufacturing industry as one of the most critical activities. In the course of the study, the authors compared different types of maintenance strategies based on reliability, advantages, disadvantages, and utilization in industry [10]. Table 1 shows a comparison between three main types of maintenance strategies.

Alencar and de Almeida (2015) discussed two decision models in equipment maintenance; reliability-centered maintenance (RCM) and multiattribute utility theory (MAUT). The RCM requires defining the safety and environmental requirement of the maintenance strategy, the constraints of the systems, functionalities, potential failures, modes of functional failures, failure consequences, and strategies to manage each failure [11]. However, a MAUT model mainly relies on distributing the weights on different factors according to the probability of occurrence. The study suggests an RCM model, where multicriteria are considered based on a MAUT model, which combines the advantages of both models [12]. Figure 2 shows a comparison between the conventional RCM approach and the multicriteria MAUT 


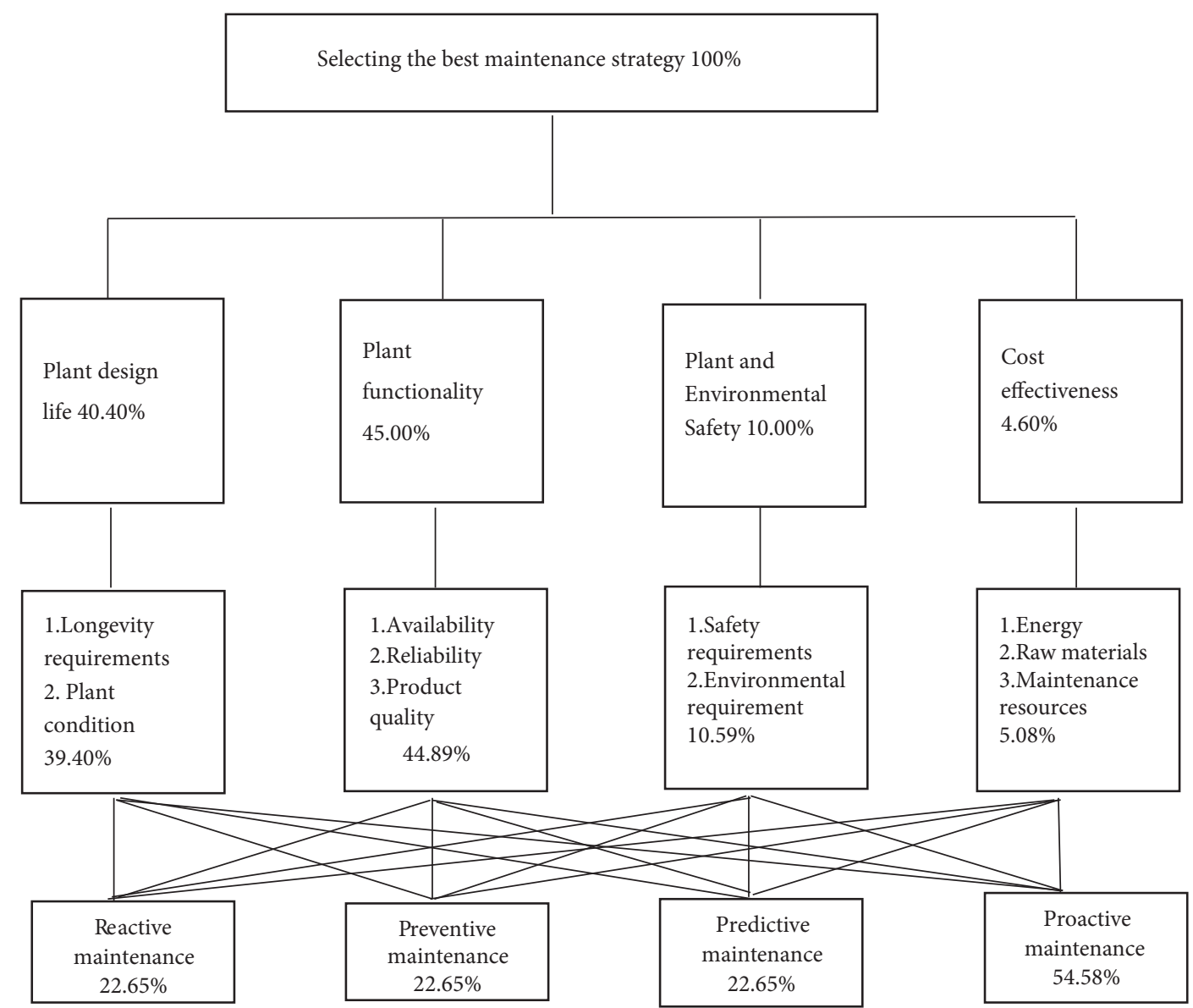

FIGURE 1: Results of Muinde et al. (2014) [8].

TABLE 1: Comparison between equipment maintenance strategies [10].

\begin{tabular}{|c|c|c|c|}
\hline Factor & Corrective & Preventive & Condition Based \\
\hline Concept & $\begin{array}{c}\text { Machine to run to failure } \\
\text { and repair or replace to } \\
\text { occur when damage is } \\
\text { apparent }\end{array}$ & $\begin{array}{l}\text { Periodic maintenance, so } \\
\text { that any possible damaged } \\
\text { parts are replaced }\end{array}$ & $\begin{array}{l}\text { Maintenance based on } \\
\text { machine condition }\end{array}$ \\
\hline Reliable for & $\begin{array}{c}\text { Small and noncritical } \\
\text { equipment, and if } \\
\text { equipment has less } \\
\text { probability to fail or system } \\
\text { is redundant }\end{array}$ & $\begin{array}{l}\text { Deteriorating and } \\
\text { consumable equipment, as } \\
\text { well as the ones with higher } \\
\text { failure pattern }\end{array}$ & $\begin{array}{l}\text { Critical equipment with } \\
\text { random failure patterns }\end{array}$ \\
\hline Pros & $\begin{array}{l}\text { Low cost and staff } \\
\text { requirements }\end{array}$ & $\begin{array}{c}\text { Flexibility } \\
\text { Increase machine life } \\
\text { Reduce failures } \\
\text { Cost saving up to } 18 \% \text { in } \\
\text { comparison with corrective }\end{array}$ & $\begin{array}{c}\text { Increase machine life } \\
\text { Decrease costs } \\
\text { Maintain product quality } \\
\text { Energy saving } \\
\text { Cost saving up to } 12 \% \text { in } \\
\text { comparison with preventive }\end{array}$ \\
\hline Cons & $\begin{array}{l}\text { Increase downtime, labor } \\
\text { costs, replacement } \\
\text { incidents }\end{array}$ & $\begin{array}{l}\text { High labor requirement } \\
\text { Unneeded maintenance } \\
\text { Damage of sound } \\
\text { components }\end{array}$ & $\begin{array}{l}\text { Increase diagnosis costs } \\
\text { Increase training costs }\end{array}$ \\
\hline Usage in industry & $55 \%$ & $31 \%$ & $12 \%$ \\
\hline
\end{tabular}



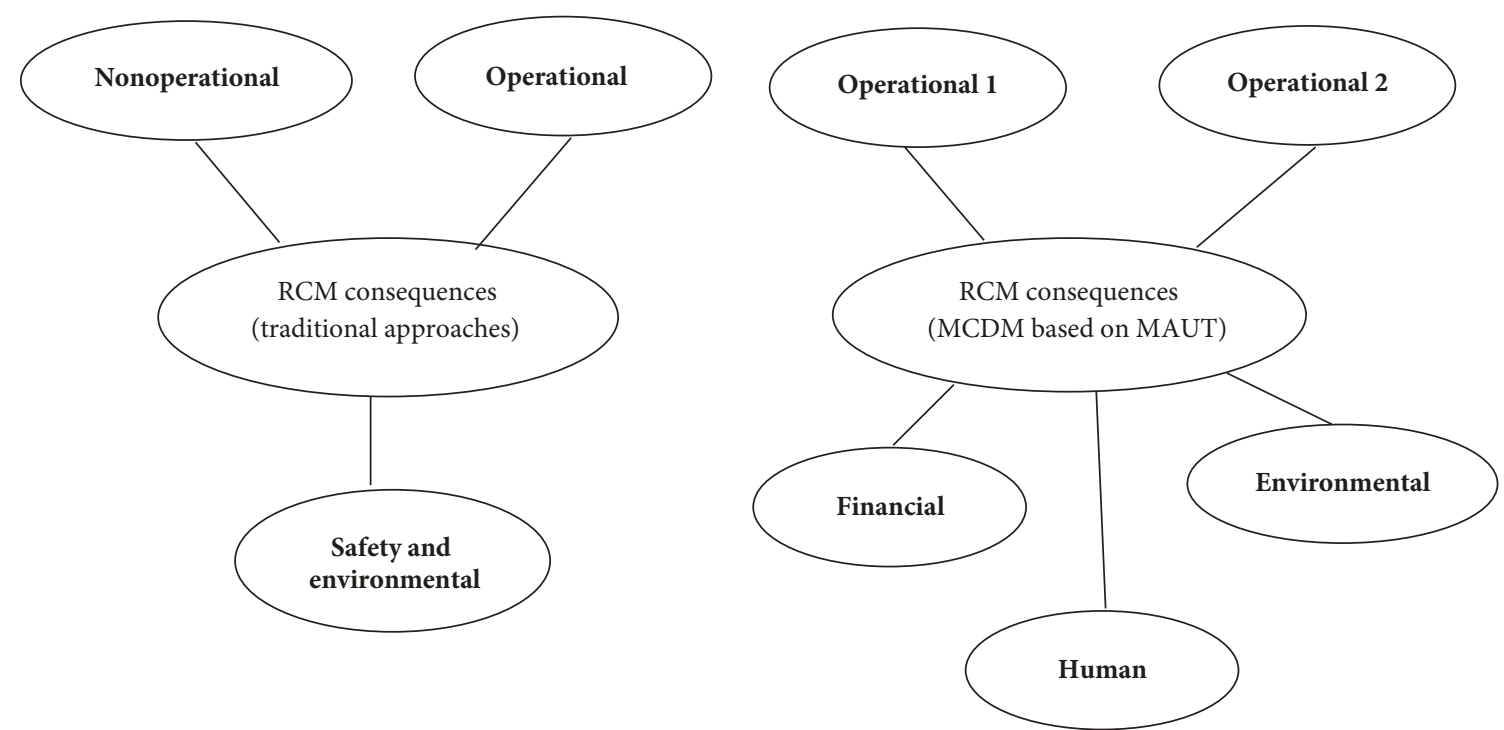

FIGURE 2: Comparison between conventional RCM and multicriteria RCM [12].

approach, where more dimensions can be included while focusing on the reliability of the system.

Chandra and Sharma (2015) endorse the total productive maintenance (TPM) strategy, which sets its goals to increase equipment efficiency and optimization, adopt a lifecycle maintenance system for the equipment, provide training to all levels of staff, and motivate staff to improve the maintenance system. The main aim of the research is to develop the TPM strategy using MCDM methods. After identifying the important attributes of the system, the alternatives are defined as corrective maintenance, RCM, and TPM strategies. Using a new least squares method, the main attributes were evaluated, where the highest weights were found for productivity (0.6053), quality (0.1323), and cost (0.0805). On the subattributes, the highest weights were found for equipment (0.42), defects in process (0.1), manpower (0.07), and energy (0.07). Based on the attributes comparison, the three alternatives were evaluated, which showed that total productive maintenance (TPM) achieved the highest scores on the majority of the attributes, except for the subattribute zero accident [13].

Azadeh and Zadeh (2016) used AHP as the MCDM method with fuzzy linguistic terms in order to increase the precision of the findings to decide between four maintenance strategy alternatives: time-based maintenance (TBM), failure-based maintenance (FBM), condition-based maintenance $(\mathrm{CBM})$, and opportunistic maintenance $(\mathrm{OM})$. Moreover, the authors identified fifteen criteria that are used for functionality simulation, which resulted into different data substituted by the fuzzy linguistic terms. Furthermore, positive and negative ideal solutions were calculated using a fuzzy TOPSIS approach, as well as the weighted distances for the alternatives. The results of the case study show that the condition-based maintenance (CBM) was ranked as the first alternative, followed by OM, FBM, and TBM, respectively [19].

\section{Hybrid Fuzzy MCDM Techniques and General Application}

In a hybrid research that aimed to select the most suitable lands of an Iranian country for urban development, the authors have chosen a fuzzy AHP and fuzzy TOPSIS procedures. The methodology is based on performing the pairwise comparison, calculating the fuzzy importance weights for each criterion, and calculating developing the alternatives' weights using the fuzzy AHP method. Moreover, the evaluation of the alternatives, separation measures, and ranking are performed through a fuzzy TOPSIS method [21].

The criteria and subcriteria, chosen for the pairwise comparison are based on the strategic studies performed by the different governmental authorities. Therefore, a total of seven main criteria and forty-four subcriteria are concluded. The results were obtained by performing a pairwise comparison using the fuzzy AHP method, which resulted into a weighted normalized matrix. Using fuzzy TOPSIS, relative closeness ratio (CC) is calculated for each alternative, which means that the higher is the value, the closer is the alternative to the ideal solution [21].

A study on life quality has used a similar process through three main phases: identifying criteria and alternatives, criteria evaluation and obtaining fuzzy weights using type-2 fuzzy AHP, and ranking the alternatives using type-2 fuzzy TOPSIS. In the second phase, the linguistic terms were used in order to form the comparison matrix. Thereafter, the fuzzy weights were calculated after ensuring that the consistency ration (CR) is below the maximum of 0.1 as per the AHP method recommendation. Moving to the third phase, alternatives were evaluated by constructing the fuzzy decision matrices using linguistic terms and the weighted matrices. Subsequently, the fuzzy ideal positive and negative solutions are calculated and compared with the relative closeness rations of the alternatives [22]. 
Other studies have followed the same approach with different applications and proven that this hybrid strategy is effective by using fuzzy AHP for comparing criteria and fuzzy TOPSIS for comparing alternatives, as it utilizes the best characteristics and advantages of these methods [23, 24]. Alternatively, simple studies have adopted a sole fuzzy MCDM method, rather than a hybrid method; however, the results were of a simple form that did not reflect the same complexity as the hybrid method $[25,26]$. Moreover, comparisons between the conventional MCDM and fuzzy MCDM results are also performed, which showed that the fuzzy technique plays a major role in yielding different results $[27,28]$.

Furthermore, the main purpose of implementing a fuzzy DEMATEL method is to establish the relationships between different criteria [29]. Similar to the fuzzy AHP method, the process starts by identifying the criteria and subcriteria that are to be compared in a pairwise system. Thereafter, the pairwise comparison is performed based on linguistic terms to indicate the influence of one criterion on the other. An initial direct relation matrix is built for further normalization and building the influential relation map (IMR) [30].

Since DEMATEL and AHP follow the same initial steps, the choice of the process depends on the goals of the research. In a study that used fuzzy DEMATEL, fuzzy AHP, and another fuzzy MCDM to select the nurse of the year, as a healthcare application, the fuzzy DEMATEL was used to identify the most influential criteria after compiling a large list by a literature review and experts' consultation. Once this task was completed, the weights were calculated by a fuzzy AHP method along with consistency verification. This approach ensures that the criteria used are interdependent on each other, which provides a more accurate and precise approach [31].

\section{Industrial Applications of MCDM}

The application of fuzzy and MCDM techniques has been used widely in the industrial applications. The most common applications that are found in the literature include but are not limited to the following:

(1) Operations and supply chain applications: using the fuzzy and MCDM methodologies in order to choose suppliers, maintenance strategies, or personnel from a pool of alternatives [25, 28, 32, 33].

(2) Technical applications: using the fuzzy and MCDM methodologies to choose from different technologies or equipment alternatives [20, 34, 35].

Multicriteria Decision-Making (MCDM) techniques are proven to help industrial organizations align their operational and business objectives with the options that they are provided with through a structural and justified process. Moreover, applying a hybrid technique that utilizes the best features of each MCDM technique can enhance the precision and reliability of the results in order to take the most informative decision [28]. The supply chain is one of the most critical structures and procedures in the industrial sector due to its impact on quality, costs, and planning. Subsequently, selecting suppliers is the starting point of the supply chain processes that has serious impacts on these crucial aspects in manufacturing $[32,33]$.

In industrial applications, there are two main factors that influence the results of the hybrid fuzzy MCDM process, which are the criteria and subcriteria selected for pairwise comparison, and the hybrid strategy chosen to carry out the different phases of the procedure [28]. Other than using the methodology to select suppliers, the fuzzy MCDM hybrid solution can be used to evaluate products and technical aspects. Equipment selection is also considered critical for industrial organizations due to its link to productivity and reliability. Thus, hybrid fuzzy MCDM methodologies are used, where using fuzzy AHP for the criteria comparison and fuzzy TOPSIS for the alternative selection is common in the literature as elaborated earlier [35].

Moreover, the hybrid fuzzy MCDM process can be integrated with industrial layout problem methods in the case of equipment selection. Such hybrid processes involve the constraints imposed by the facility as selection criteria. In a study that involved purchasing equipment from different manufacturers, the authors used fuzzy AHP and entropy to evaluate the criteria and fuzzy TOPSIS to evaluate the alternative, as the first stage of the study. In the second stage, a layout problem methodology, AUGNECON, was used to involve the facility constraints and solve the case as a facility layout problem, as shown in the process chart in Figure 3 [34].

Furthermore, hybrid fuzzy MCDM methodologies have been used to compare technology options. In a study that compared renewable energy technology options, a complex integration of MCDM methods is carried out. After a read into the literature, the authors defined criteria, subcriteria and alternatives and obtained the expert's opinion on their priority and importance, and matrices were constructed with linguistic terms. Thereafter, fuzzy DEMATEL and fuzzy ANP were performed simultaneously, which started by acquiring consensus from the results by performing normalization of direct-relation matrices and aggregation for the two processes, respectively. Once results are obtained from both processes, a unified matrix was constructed using both results and normalized. After obtaining criteria weights, a fuzzy TOPSIS method is followed in order to rank alternatives and producing final results [20].

\section{Maintenance Application and Model Design}

Based on the previous review of the different MCDM methodologies and fuzzy approaches, as well as the hybrid methods that have been covered in the literature, the model design used in this research is provided by the following steps:

(1) Process chart design for the model incorporating fuzzy AHP, fuzzy DEMATEL, and fuzzy TOPSIS

(2) Criteria selection which is used for pairwise comparison by the experts and matrices development

(3) Different maintenance strategies and policies that are covered in the literature using MCDMs in order to develop the alternatives for the process 


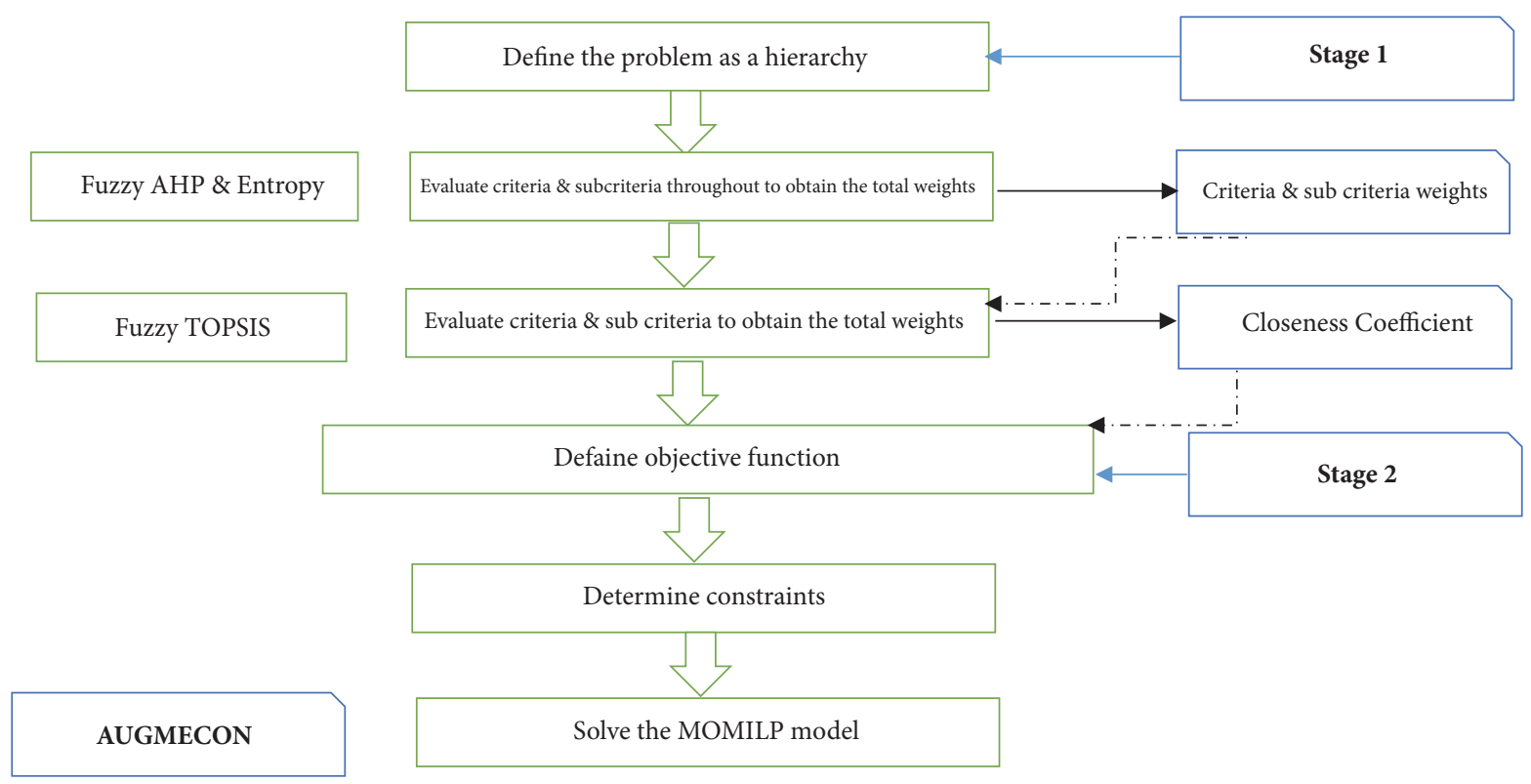

FIGURE 3: Hybrid fuzzy MCDM application integrated with facility layout problem for equipment selection in industrial application [34].

5.1. Model Design. In order to be able to design the model based on the three chosen methodologies, more than twenty articles using fuzzy hybrid methodologies were studied. In this section, the most significant papers are reviewed based on their objectives and the ability of the chosen methodologies to achieve them. Moreover, the strengths and weaknesses of the papers are assessed for consideration in the present study.

Dardas et al. (2014) have used a hybrid method of fuzzy AHP for weights' calculation and fuzzy TOPSIS for ranking alternatives. The authors recognized the AHP's most strong advantage as being based on a pairwise comparison and the consistency ratio limit that is required by the method. Since AHP has a disadvantage of not being able to reduce the number of alternatives, the TOPSIS methodology is applied, which has a great advantage as being very efficient in calculating perfect solutions and comparing the available alternatives to them with a closeness ratio (CC). The main objective set by the research is to identify the most suitable lands for development through identifying several criteria that were pairwise compared and its weights calculated using the fuzzy AHP method. Furthermore, the different nominated lands were compared with the ideal solutions calculated using the fuzzy TOPSIS method, which is considered as a useful method to assess real-life problems through comparing solutions to the most ideal. The results of the study show that the authors were successful in achieving their objectives as they calculated the weights using the pairwise comparison with consistency ratios less than 0.1 , then proceeded to calculating ideal solutions and ranking the nominated lands using the fuzzy TOPSIS method [21].

Sahın and YapıcıPehlivan (2017) have used a hybrid methodology using fuzzy-2 AHP method for weights calculation and fuzzy-2 TOPSIS for alternatives ranking. However, the article did not present valid reasons to the reason they have chosen these two methods for their study as the ones provided in Dardas et al. (2014). Nonetheless, the method had been carried out similarly, with the difference in the fuzzy type, by performing the pairwise comparison using the AHP method, checking for consistency ratios, and calculating the weights, which are then passed to the TOPSIS's decision matrix. On the other side, the alternatives are compared using the TOPSIS method and the result is integrated with the AHP results in the decision matrix. Furthermore, the ideal negative and positive solutions were calculated, and the alternatives' relative closeness is calculated in order to rank them [22].

Sputro and Rouyendegh (2015) identified using a hybrid fuzzy AHP and TOPSIS method as a classical methodology that is ideally used to solve solutions based on human opinion that can be indecisive and vague. The authors presented the biggest advantage of using the AHP method for its ability to indicate the usefulness of the data through the consistency testing that is performed after obtaining the data. Moreover, several advantages are presented for the TOPSIS method, including calculating best and worst scenarios for comparison with the alternatives, simulating the human decision-making process through a mathematical model, easiness of algorithm for implementation, and the visualization of alternatives' performance measures on a polyhedron. While the study has incorporated a facility layout problem procedure for the application of selecting equipment at the end of the process, the first two steps of the chart used fuzzy AHP for pairwise comparison and weights calculation, and fuzzy TOPSIS for alternatives weights' calculation. These two steps successfully led the authors to the selection of equipment using best- and worst-case scenarios and by comparing several criteria and subcriteria using the hybrid fuzzy methodology [34].

Taati and Esmaili-Dooki (2017) have incorporated fuzzy DEMATEL steps before proceeding to the weights calculation 
by a fuzzy AHP method. The DEMATEL method uses a pairwise comparison between the criteria and subcriteria, similar to the AHP method; however, while the AHP method compares the criteria based on their importance, the DEMATEL method is used to identify the interdependencies between the criteria. For that study, the authors had the objective of calculating the relationships between the criteria and used the AHP method for weights calculation, which combines the two advantages of both methodologies and establishes a double-degree relationship between the criteria: importance and interdependencies. Nevertheless, for alternatives comparison, the authors used fuzzy VIKOR method without providing a justification of this hybrid approach [31].

Büyüközkan and Güleryüz (2017) give the same advantages of using a hybrid fuzzy DEMATEL and fuzzy ANP methodologies to establish the relationships between the criteria using a pairwise comparison, as well as using a hybrid ANP and TOPSIS approach to utilize the latter method's advantage for ranking the alternatives based on positive and negative scenarios. The authors claim using the hybrid DEMTAL, ANP, and TOPSIS approaches as the first of its kind for their research, while using fuzzy preferences in three methods to utilize its advantage in decreasing ambiguity and uncertainty resulting from the human decision-making process. Based on a literature review performed by the authors of nineteen of the most recent hybrid approaches of the three methods, in addition to the AHP method, none of the studies have incorporated a hybrid fuzzy approach using DEMATEL-AHP-TOPSIS methodology. The use of ANP method as part of the research imposes a more lengthy and complex procedure by constructing a super matrix for all the preferences [20].

In this research, a hybrid fuzzy approach using DEMATEL-AHP-TOPSIS methods is utilized in order to perform a pairwise comparison between criteria through fuzzy DEMATEL and fuzzy AHP and rank the alternatives based on the integrated matrix utilizing fuzzy TOPSIS. This approach establishes two relationships between the chosen criteria based on their relative importance and interdependencies using AHP and DEMATEL, respectively. Nonetheless, using the AHP method, rather than the ANP method, provides a simpler implementation and calculation procedure. The method proceeds into calculating the positive and negative solutions based on the results, ranking alternatives and calculating their relative closeness to ideal solutions using the fuzzy TOPSIS method. Furthermore, the used method can be claimed as the first application of this hybrid approach (DEMATEL-AHP-TOPSIS), especially for maintenance strategy/policy selection. The fuzzy linguistic terms are also used with the three methods in order to eliminate ambiguity and uncertainty resulting from the human decision-making process, which is proven to be successful for that purpose through the literature. Subsequently, the results are compared with literature through the discussion part of this thesis in order to assess the success of the method and its ability to enhance the decision-making process using a simpler hybrid methodology utilizing the best characteristics of the used MCDM methods.
The model is based on the best practices found through the review of the literature on fuzzy DEMATEL, fuzzy AHP, and fuzzy TOPSIS methodologies and the hybrid applications in general as well as industrial applications. Therefore, Figure 4 is the model design process chart using the three methodologies for establishing interrelationships between the criteria, weights calculation and aggregation of linguistic fuzzy score, and ranking of alternatives, respectively. The process steps are narrated; however, structure that includes equations is provided in a future application of the study.

Step 1. Review of literature for process, criteria, subcriteria, and alternatives of maintenance strategies.

Step 2. Using a fuzzy DEMATEL approach, criteria are compared to establish the relationships between the different criteria and subcriteria and build total relation matrix.

Step 3. Calculate inner dependence matrix from total relation matrix.

Step 4. Develop questionnaires with pairwise comparison as per fuzzy AHP method and use linguistic fuzzy score.

Step 5. Obtain the fuzzy AHP matrix, calculate relative importance weights, and normalize matrices.

Step 6. Check consistency ratio. If less than 0.1, process continues, if not repeat Step 5.

Step 7. Calculate relative importance weights and normalize matrices

Step 8. Construct a matrix incorporating fuzzy AHP and fuzzy DEMATEL results.

Step 9. Evaluate alternatives' weights using fuzzy TOPSIS

Step 10. Calculate positive and negative ideal solutions and the relative closeness of each alternative.

Step 11. Rank alternatives according to their priority.

5.2. Criteria Selection and Alternatives. As the process designed for this study starts with a fuzzy AHP method, criteria and subcriteria shall be compared according to their priority and importance in a pairwise structure. The comparison is carried out by experts in the field in order to obtain data based on knowledge, experience, and research. Further information about the experts is provided in the case study of this thesis. Through a survey of the literature, as shown in Table 2, several main criteria and subcriteria are found as follows:

(1) Safety and security includes the personnel or human safety, environment safety, facility, and machine safety. This is one of the criteria, where all of its subcriteria are mentioned in the majority of the literature.

(2) Cost refers to production that could be damaged in case of the strategy failure, in addition to the loss 


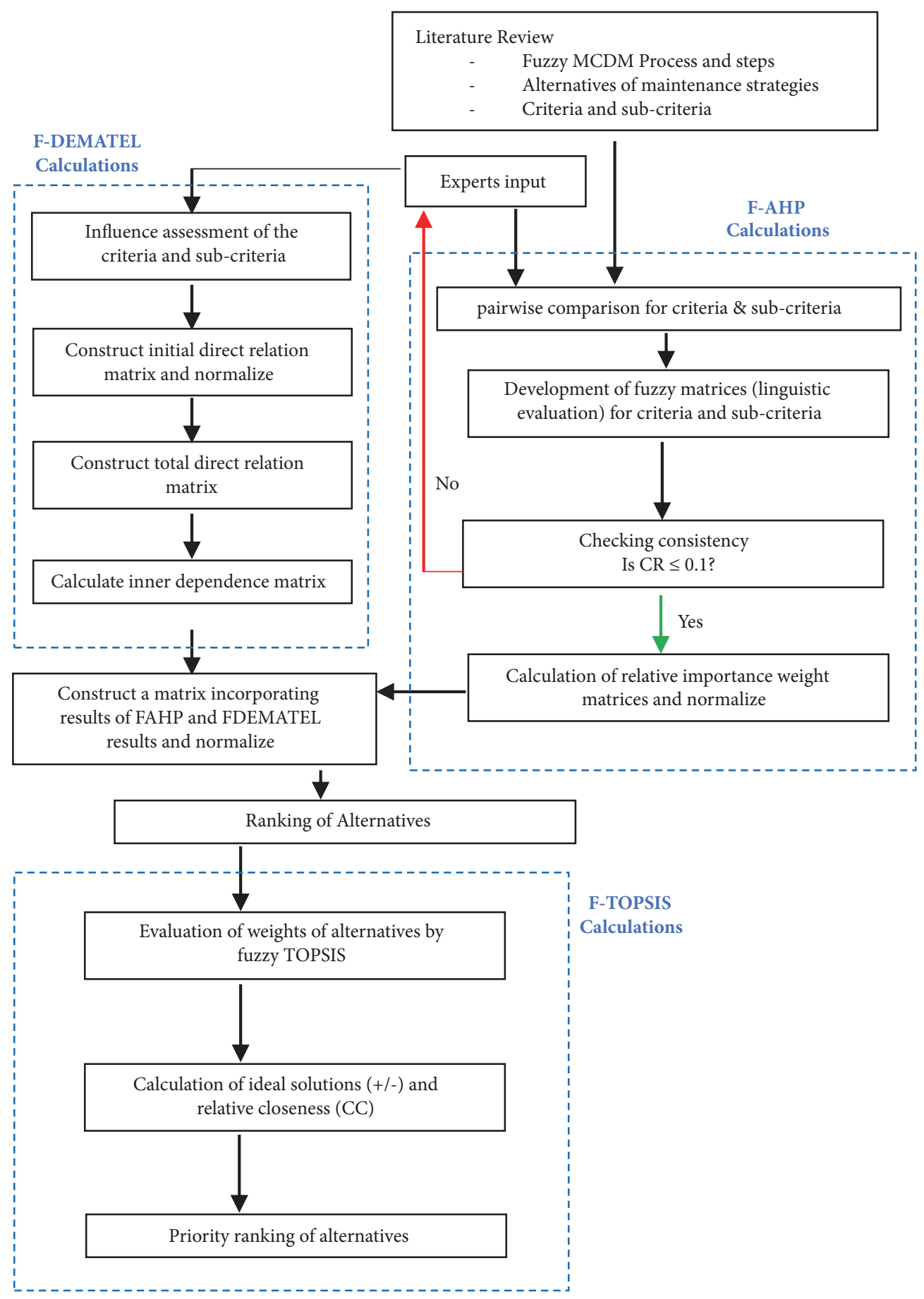

FIGURE 4: Process chart of the model design of the research.

in production. Moreover, the cost of workers and specialists forms a significant part of these criteria, which includes labor costs, training costs, and specialized employee costs. Further, this criterion includes spare parts and hardware costs that are used in the maintenance operations.

(3) Reliability means that the maintenance policy has to ensure the minimum time and cost impacts on operations. Therefore, this criterion has five subcriteria, including the ability of the strategy to preserve significant items within the facility, maximize time between failures, provide inspections with no diagnostic errors, keep all equipment and machine accessible for inspections, and implement reliable techniques.

(4) Availability measures the three subcriteria, including the average time of repair and the ability to minimize it, the presence of the maintenance team and required 
TABLE 2: Criteria and subcriteria for selection of maintenance strategy using fuzzy-MCDM hybrid methodology.

\begin{tabular}{|c|c|c|}
\hline Criteria & Subcriteria & Reference \\
\hline \multirow{3}{*}{$\begin{array}{l}\text { Safety \& } \\
\text { Security }\end{array}$} & Human safety & {$[14-17]$} \\
\hline & Environment safety & [14-17] \\
\hline & Facility and machine safety & {$[14-18]$} \\
\hline \multirow{5}{*}{ Cost } & Damage and loss in production & {$[14,16,18]$} \\
\hline & Spare parts costs/ hardware & [14-17] \\
\hline & $\begin{array}{c}\text { Programming maintenance and } \\
\text { software }\end{array}$ & {$[14-18]$} \\
\hline & Training costs & {$[15,16,18]$} \\
\hline & $\begin{array}{l}\text { Labor and specialized employees' } \\
\text { costs }\end{array}$ & {$[14,17,18]$} \\
\hline \multirow{3}{*}{ Reliability } & Average time between failures & {$[14,15,18]$} \\
\hline & $\begin{array}{c}\text { Inspection accessibility and } \\
\text { errors-free }\end{array}$ & {$[14-16,18]$} \\
\hline & Reliability of techniques & {$[16,18]$} \\
\hline \multirow{3}{*}{ Availability } & Average time for repair & {$[14,15,18]$} \\
\hline & Inherent availability & [14] \\
\hline & On demand availability & {$[14]$} \\
\hline \multirow{3}{*}{ Feasibility } & Acceptance by personnel/labor & {$[15,16]$} \\
\hline & Effectiveness of policy & {$[15]$} \\
\hline & Access to technology & {$[17]$} \\
\hline \multirow{3}{*}{ Added-Value } & Production quality & {$[17,18]$} \\
\hline & Reduction of waste & {$[17,18]$} \\
\hline & Spare parts inventory & {$[15-17]$} \\
\hline
\end{tabular}

items permanently, and the ability of the strategy to provide on demand and emergency cases.

(5) Feasibility refers to the acceptance of the workers of the strategy socially and professionally. Moreover, the criterion includes the efficiency of the strategy to perform tasks effectively and the accessibility to the technology required of the strategy.

(6) Added-value is the ability of the strategy to enhance the production and economics of the facility by increasing production quality, decreasing its waste, and minimizing spare parts inventory.

Furthermore, it is important to specify the alternatives that are compared in this process using fuzzy TOPSIS method. Through the literature, there are different classifications. In a study that investigated maintenance strategies in the oil and gas industry, the following points are concluded and identified according to the conditions that control its occurrence $[14,15]$ :

(1) Corrective maintenance occurs after incidents

(2) Time-based maintenance occurs regularly based on a schedule

(3) Condition-based maintenance occurs based on certain events or for certain sensitive and complex equipment

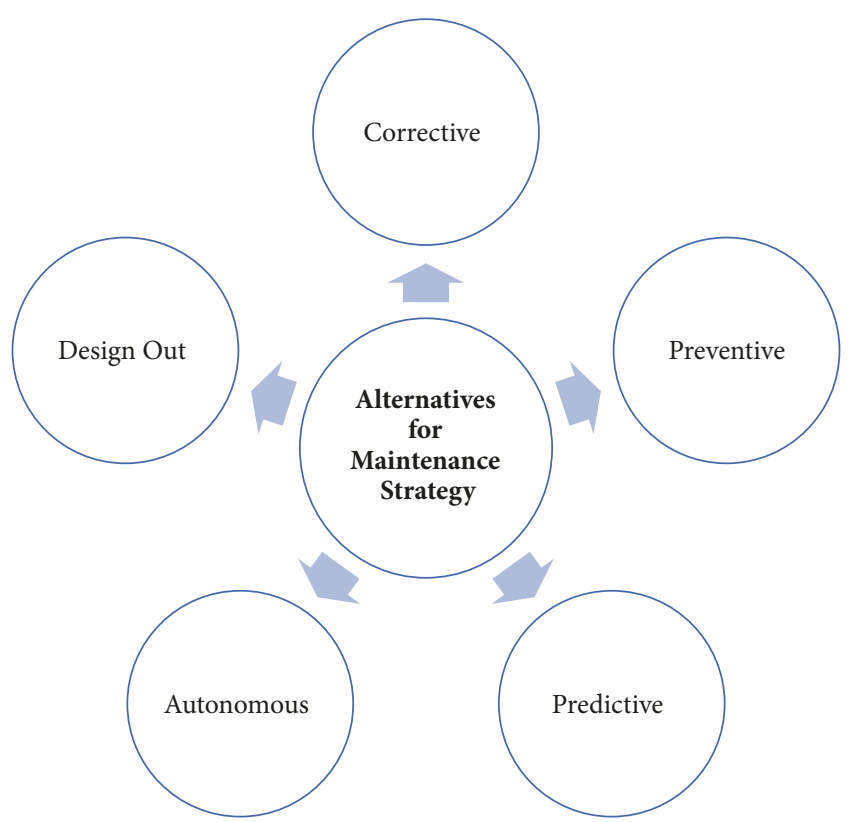

FIGURE 5: Alternative identified through the literature for maintenance strategies [14-17, 36, 37].

In addition, the literature provided five types of maintenance policies, which start with corrective maintenance that is traditionally used but has its disadvantages economically. Moreover, preventive maintenance is conducted regularly in order to ensure that production and machines are operating without any issues. Predictive maintenance is a strategy that prioritize specific equipment for its complexity, which is similar to condition-based maintenance $[14,16,17,36]$.

Another type of maintenance policy is autonomous or detection based, which distributes the maintenance responsibilities on its team, as well as the labor operating or monitoring the equipment. Thus, this type of strategy requires special training programs to be provided for the labor, besides operational training. The fifth type is addressed as design-out maintenance, which addresses the defaults of the equipment by studying its design, identifying the risky items, and substituting them by more reliable ones, considering costs, efficiency, productivity, and capacity [15, 16, 36, 37].

Based on the above definitions, there are five final alternative maintenance strategies and polices that are identified, as shown in Figure 5. These alternatives are going to be used in the fuzzy TOPSIS part of the designed model of this research.

\section{Model Demo Application}

The developed model in the research is based on two research points.

MCDM methods, and their combinations, used for maintenance strategy selection, and achieved efficient results in solving other types of problems.

Through the research, maintenance strategy selection studies were observed to use different MCDM methods, which led to achieving different results. Moreover, there were 
some studies that combined MCDMs with linguistic terms and succeeded in achieving efficient results by using the strengths of each MCDM approach in the decision-making process in solving more complex problems, such as choosing a renewable energy system for a country [20]. The designed model solves the problem of choosing a maintenance strategy using an efficient algorithm combination from three MCDM methods.

The demo application provided in this section is meant to show the process rather than convey specific results. Büyüközkan and Güleryüz [20] used the combination of fuzzy ANP-DEMATEL-TOPSIS to select a renewable energy source for Turkey. The results were acceptable because it used the interrelationships between criteria created by the ANP and DEMATEL, in addition to the pairwise comparison of the ANP, and used TOPSIS to rank the alternatives, as the method was proven to give reliable results in that aspect. Therefore, the study of Büyüközkan and Güleryüz can be a benchmark to the machine learning approach proposed by the model in this study.

The developed model in this study performs pairwise comparison using AHP, establishes interrelationships between criteria using DEMATEL and evaluates the alternatives using TOPSIS. Through such a model, a simpler MCDM integration can be used for a less dynamic problem, i.e., selecting a maintenance strategy through a hybrid MCDM approach with linguistic terms, when compared to the benchmark study. This method would decrease the length of judgements imposed by the ANP method, while using the three methods for their best characteristics: pairwise comparison (AHP), interrelations (DEMATEL), and alternatives ranking (TOPSIS). The criteria used in maintenance strategy selection are more solid/less dynamic than the ones used for renewable energy sources selection in a country, for instance. The model used by Büyüközkan and Güleryüz is a good model for the problem presented; however, there is no need to establish complex correlations through using ANP and DEMATEL for the current study problem. A study that compared using a hybrid of DEMATEL-ANP with ANP to select a project for healthcare organizations with six sigma alternatives [38] recommended using DEMATEL-ANP hybrid as the feedback after implementation is taken into consideration. Nevertheless, the selection of a healthcare project is very complex as it considers medical and administrative aspects. Hence, intercorrelations need to be very strong. The study also highlights a disadvantage for using the DEMATEL-ANP hybrid as it imposes additional judgement that is considered not necessary for the current study. Therefore, the model developed in Figure 4 aims to create a simpler solution that can be applied and used for decision making in maintenance strategy selection and similar problems, as well as providing reliable results.

A demo application is presented in this paper in order to show the process and possible outcomes of the model designed in this study. Firstly, the criteria and subcriteria are evaluated through verbal terms and subsequently defined on a fuzzy linguistic scale, as shown in Table 3. Tables 4 and 5 show a demo evaluation of the main criteria through the fuzzy AHP and fuzzy DEMATEL matrices by two experts,
TABLE 3: Evaluation of verbal and linguistic terms [20].

\begin{tabular}{lc}
\hline Linguistic Variables & Fuzzy Scales \\
\hline S8: Certain (C) & $(1.00,1.00,0.00,0.00)$ \\
S7: Extremely likely (EL) & $(0.98,0.99,0.05,0.01)$ \\
S6: Most likely (ML) & $(0.78,0.92,0.06,0.05)$ \\
S5: Meaningful chance (MC) & $(0.63,0.80,0.05,0.06)$ \\
S4: It may(IM) & $(0.41,0.58,0.09,0.07)$ \\
S3: Small chance (SC) & $(0.22,0.36,0.05,0.06)$ \\
S2: Very low chance (VLC) & $(0.10,0.18,0.06,0.05)$ \\
S1: Extremely likely (EU) & $(0.01,0.02,0.01,0.05)$ \\
S0: Impossible (I) & $(0.00,0.00,0.00,0.00)$ \\
\hline
\end{tabular}

TABLE 4: Criteria of evaluation using fuzzy AHP and fuzzy DEMATEL - Expert 1 [20].

\begin{tabular}{ccccccccccc}
\hline & \multicolumn{1}{c}{$\mathrm{C} 1$} & \multicolumn{2}{c}{ C2 } & \multicolumn{2}{c}{ C3 } & \multicolumn{2}{c}{ C4 } & \multicolumn{2}{c}{ C5 } \\
\hline C1 & - & - & SC & MC & IM & IM & VLC & IM & SC & ML \\
C2 & SC & MC & - & - & SC & EL & VLC & IM & VLC & IM \\
C3 & IM & IM & VLC & MC & - & - & EU & EU & EU & VLC \\
C4 & IM & ML & IM & ML & EL & EL & - & - & VLC & IM \\
C5 & VLC & MC & IM & ML & ML & EL & IM & ML & - & - \\
\hline
\end{tabular}

TABLE 5: Criteria of evaluation using fuzzy AHP and fuzzy DEMATEL - Expert 2 [20].

\begin{tabular}{ccccccccccc}
\hline & \multicolumn{1}{c}{$\mathrm{C} 1$} & \multicolumn{2}{c}{ C2 } & \multicolumn{2}{c}{ C3 } & \multicolumn{2}{c}{ C4 } & \multicolumn{2}{c}{ C5 } \\
\hline C1 & - & - & SC & IM & SC & IM & SC & SC & SC & IM \\
C2 & IM & MC & - & - & SC & EL & VLC & IM & VLC & IM \\
C3 & IM & MC & EU & MC & - & - & EU & VLC & EU & SC \\
C4 & MC & MC & IM & ML & ML & EL & - & - & VLC & IM \\
C5 & IM & MC & IM & ML & MC & EL & IM & ML & - & - \\
\hline
\end{tabular}

TABLE 6: Collective evaluation with fuzzy relation [20].

\begin{tabular}{ccccccccccc}
\hline & \multicolumn{1}{c}{$\mathrm{C} 1$} & \multicolumn{2}{c}{$\mathrm{C} 2$} & \multicolumn{2}{c}{$\mathrm{C} 3$} & \multicolumn{2}{c}{ C4 } & \multicolumn{2}{c}{ C5 } \\
\hline C1 & - & - & VLC & MC & SC & MC & VLC & MC & SC & ML \\
C2 & SC & ML & - & - & SC & EL & VLC & MC & VLC & IM \\
C3 & SC & MC & EU & MC & - & - & EU & VLC & EU & SC \\
C4 & SC & ML & SC & ML & ML & EL & - & - & VLC & IM \\
C5 & VLC & MC & IM & ML & MC & EL & IM & ML & - & - \\
\hline
\end{tabular}

respectively. Moreover, Table 6 shows the collective linguistic fuzzy relations that are resulting from the fuzzy AHP and fuzzy DEMATEL relations. Furthermore, the alternatives are evaluated using the same linguistic terms provided in Table 3 through five criteria. Each criterion is assessed against each of the alternatives, as shown in Table 7 Fuzzy TOPSIS equations are applied to the evaluation using linguistic and crisp terms in order to rank the alternatives. As shown in Table 8, the different alternative evaluations have produced different results. While linguistic terms have shown that the fifth alternative has the highest preference score, the crisp DEMATEL-AHP-TOPSIS assessment has shown that the fourth alternative has the highest preference score. 
TABLE 7: Alternative evaluation of collective direct matrix [20].

\begin{tabular}{ccccccccccccccccccccc}
\hline & C11 & C12 & C13 & C14 & C15 & C21 & C22 & C23 & C24 & C25 & C31 & C32 & C33 & C34 & C41 & C42 & C43 & C51 & C52 & C53 \\
\hline A1 & MC & C & C & VLC & C & EL & C & C & C & EL & EL & ML & C & MC & C & EL & ML & EL & EL & C \\
A2 & MC & C & C & I & C & MC & C & C & EL & VLC & EL & EL & C & MC & ML & C & VLC & EL & MC & C \\
A3 & C & EL & EL & I & C & ML & ML & MC & EL & VLC & EL & EL & C & EL & C & C & ML & C & C & C \\
A4 & EL & EL & MC & C & C & C & EL & C & C & C & C & EL & C & EL & IM & VLC & ML & EL & ML & MC \\
A5 & C & C & C & IM & C & IM & EL & EL & C & IM & EL & C & C & EL & C & EL & MC & MC & C & EL \\
\hline
\end{tabular}

TABLE 8: Alternative final preference scores using linguistic and crisp terms [20].

\begin{tabular}{lcccc}
\hline & $\begin{array}{c}\text { Linguistic interval } \\
\text { fuzzy preferences } \\
\text { with DEMATEL AHP } \\
\text { TOPSIS }\end{array}$ & Ranking & $\begin{array}{c}\text { Crisp } \\
\text { DEMATEL } \\
\text { AHP TOPSIS }\end{array}$ & Ranking \\
\hline A1 & 0.549 & 5 & 0.513 & 3 \\
A2 & 0.550 & 4 & 0.466 & 4 \\
A3 & 0.630 & 2 & 0.465 & 5 \\
A4 & 0.559 & 3 & $\mathbf{0 . 7 2 4}$ & $\mathbf{1}$ \\
A5 & $\mathbf{0 . 6 6 5}$ & $\mathbf{1}$ & 0.535 & 2 \\
\hline
\end{tabular}

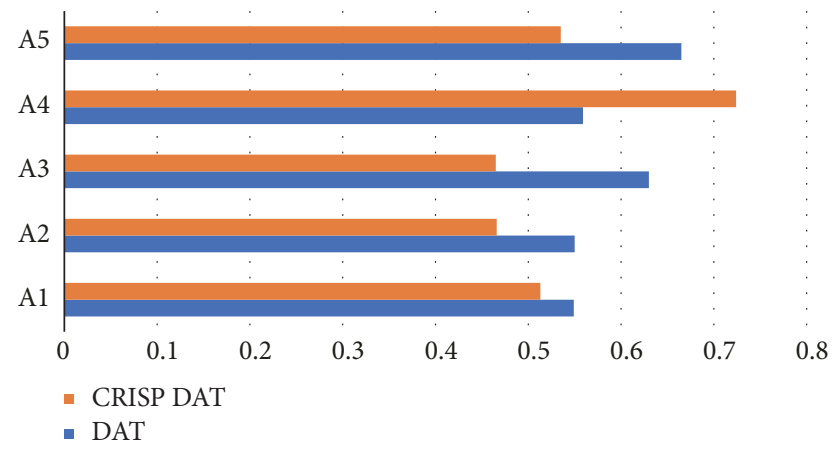

FIGURE 6: Overall performance of the alternatives.

Linguistic interval fuzzy preferences with DEMATELAHP-TOPSIS (DET) approach in five alternatives have been utilized. This clearly shows that alternative 5 is ranked first and alternative 4 ranked last. In short, A5(0.665)> $\mathrm{A} 3(0.630)>\mathrm{A} 4(0.559)>\mathrm{A} 2(0.550)>\mathrm{A} 1(0.549)$, and Crisp DEMATEL AHP-TOPSIS (Crisp DET): A4(0.724)> $\mathrm{A} 5(0.535)>\mathrm{A} 1(0.513)>\mathrm{A} 2(0.466)>\mathrm{A} 3(0.465)$. Figure 6 shows the overall performance of the alternatives.

\section{Conclusion and Further Work}

As shown in the above review for the usage of fuzzy MCDM techniques in several general and industrial complex decision-making applications, several fuzzy MCDM applications have been found in the literature. However, this study marks one of a kind application by applying a hybrid method of F-AHP, F-DEMATEL and F-TOPSIS.
Furthermore, the model of the study has been designed to incorporate the three methodologies in a complete decisionmaking model. The research will use the model for maintenance strategy selection application. Therefore, the main criteria and subcriteria have been identified in order to be able to apply the F-AHP and F-DEMATEL parts of the model. Six different maintenance strategies have been compiled for the alternatives' ranking by F-TPOSIS.

A demo application is shown in the paper to allow the reader to understand the logic and purpose behind using the proposed model, which developed based on a benchmark model proven by Büyüközkan and Güleryüz [20] and achieved acceptable and reliable results. The proposed model includes performing a pairwise comparison between criteria (F-AHP), establishing interrelationships between criteria (FDEMATEL), and ranking alternatives for maintenance strategies (F-TOPSIS). Such a model uses the strength characteristics of each selected MCDM method in order to provide reliable solutions for the research problem, while keeping the complexity of the judgements within the required level. Moreover, process steps are shown in the demo application to clarify them using an application by the benchmark study.

The next step for this research is the model application, where the questionnaires for the AHP, DEMATEL, and TOPSIS methodologies have been constructed from the input of experts. Subsequently, the pairwise and interrelationship scales are substituted with the fuzzy terms. Finally, the alternatives are ranked using F-TOPSIS by calculating the negative and positive ideal solutions and comparing the alternatives scorings with them. The results of the application of the presented model are issued in a further study.

\section{Data Availability}

The data used to support the findings of this study are available from the corresponding author upon request.

\section{Conflicts of Interest}

The authors declare that they have no conflicts of interest.

\section{References}

[1] E. Triantaphyllou, B. Shu, S. Nieto Sanchez, and T. Ray, "MultiCriteria Decision Making: An Operations Research Approach," in Encyclopedia of Electrical and Electronics Engineering, J. G. Webster, Ed., vol. 15, pp. 175-186, John Wiley \& Sons, New York, USA, 1998. 
[2] S. J. Chen and C. L. Hwang, Fuzzy Multiple Attribute Decision Making: Methods and Applications, vol. 375 of Lecture Notes in Economics and Mathematical Systems, Springer, New York, NY, USA, 1992.

[3] A Özdağoğlu and G. Özdağoğlu, "Comparison of AHP and Fuzzy AHP for the Multi-Criteria Decision Making Processes with Linguistic Evaluation," Istanbul Ticaret Üniversitesi Fen Bilimleri Dergisi, vol. 6, no. 11, pp. 65-85, 2007.

[4] R. Samant, S. Deshpande, and A. Jadhao, "Survey on Multi Criteria Decision Making Methods," International Journal of Innovative Research in Science, Engineering and Technology, vol. 4, no. 8, pp. 7175-7178, 2015.

[5] A. Gabus and E. Fontela, World Problems an Invitation to Further Thought within the Framework of DEMATEL, Battelle Geneva Research Centre, Geneva, Switzerland, 1972.

[6] R. Wang and S. J. Chuu, "Group decision-making using a fuzzy linguistic approach for evaluating the flexibility in a manufacturing system," European Journal of Operational Research, vol. 154, no. 3, pp. 563-572, 2004.

[7] G. H. Tzeng, C. H. Chiang, and C. W. Li, "Evaluating intertwined effects in e-learning programs: a novel hybrid MCDM model based on factor analysis and DEMATEL," Expert Systems with Applications, vol. 32, no. 4, pp. 1028-1044, 2007.

[8] P. M. Muinde, P. N. Muchiri, and B. W. Ikua, "Maintenance Strategy Selection Using Analytic Hierarchy Process: A Case Study," Journal of Sustainable Research in Engineering, vol. 1, no. 4, pp. 21-29, 2014.

[9] S. Karthik, A. Manimaran, S. Sekar, and J. Silkson John, "Optimizing maintenance strategy using simulation based AHP," International Journal of Mechanical Engineering and Technology, vol. 8, no. 9, pp. 104-111, 2017.

[10] S. K. Chandrahas, D. Mishra, and Mahapatra., "Maintenance Strategy and Decision Making - AHP Method," International Journal of Advanced Engineering Research and Studies, vol. 4, no. 2, pp. 256-258, 2015.

[11] I. Emovon, R. A. Norman, and A. J. Murphy, "Elements of maintenance systems and tools for implementation within the framework of Reliability Centred Maintenance- A review," Journal of Mechanical Engineering and Technology, vol. 8, no. 2, pp. 1-34, 2016.

[12] M. H. Alencar and A. T. de Almeida, "A multicriteria decision model for assessment of failure consequences in the RCM approach," Mathematical Problems in Engineering, vol. 2015, Article ID 729865, 10 pages, 2015.

[13] S. Chandra and S. K. Sharma, "Multi criteria decision model $(\mathrm{MCDM})$ for the evaluation of maintenance practices and implementation of total productive maintenance (TPM) in indian industries," International Journal of Engineering Research and Applications, vol. 5, no. 9, pp. 17-28, 2015.

[14] A. M. Mohamed and S. M. Saad, "Fuzzy analytic hierarchy process for the selection of maintenance policies within petroleum industry," in Proceedings of the 14th International Conference on Manufacturing Research, ICMR 2016, pp. 529-534, UK, September 2016.

[15] H. Xie, L. Shi, and H. Xu, “Transformer maintenance policies selection based on an improved fuzzy analytic hierarchy process," Journal of Computers (Finland), vol. 8, no. 5, pp. 1343-1350, 2013.

[16] L. Wang, J. Chu, and J. Wu, "Selection of optimum maintenance strategies based on a fuzzy analytic hierarchy process," International Journal of Production Economics, vol. 107, no. 1, pp. 151163, 2007.
[17] M. Momeni, M. R. Fathi, M. K. Zarchi, and S. Azizollahi, "A Fuzzy TOPSIS-Based Approach to Maintenance Strategy Selection: A Case Study," Middle-East Journal of Scientific Research, vol. 8, no. 3, pp. 699-706, 2011.

[18] M. Akhshabi, "A New Fuzzy Multi Criteria Model for Maintenance Policy," Middle-East Journal of Scientific Research, vol. 10, no. 1, pp. 33-38, 2011.

[19] A. Azadeh and S. Abdolhossein Zadeh, "An integrated fuzzy analytic hierarchy process and fuzzy multiple-criteria decisionmaking simulation approach for maintenance policy selection," Simulation, vol. 92, no. 1, pp. 3-18, 2016.

[20] G. Büyüközkan and S. Güleryüz, "Evaluation of Renewable Energy Resources in Turkey using an integrated MCDM approach with linguistic interval fuzzy preference relations," Energy, vol. 123, pp. 149-163, 2017.

[21] M. Dadras, H. Z. M. Shafri, N. Ahmad, B. Pradhan, and S. Safarpour, "A combined fuzzy MCDM approach for identifying the suitable lands for Urban development: An example from bandar ABBS, Iran," Journal of Urban and Environmental Engineering, vol. 8, no. 1, pp. 11-27, 2014.

[22] A. Sahın and N. Yapıcı Pehlivan, "Evaluation of life quality by integrated method of ahp and topsis based on interval type-2 fuzzy sets," Hacettepe Journal of Mathematics and Statistics, vol. 46, no. 3, pp. 519-531, 2017.

[23] A. Esmaili-Dooki, P. Bolhasani, and M. Fallah, "An integrated fuzzy AHP and fuzzy TOPSIS approach for ranking and selecting the chief inspectors of bank: A case study," Journal of Applied Research on Industrial Engineering, vol. 4, no. 1, pp. 823, 2017.

[24] S. Mahmoodzadeh, J. Shahrabi, M. Pariazar, and M. S. Zaeri, "Project selection by using fuzzy AHP and TOPSIS technique," International Journal of Industrial and Manufacturing Engineering, vol. 1, pp. 270-275, 2007.

[25] Doğanalp, "Maintenance manager selection process with fuzzy topsis technique: an empirical application," The Journal of Social and Economic Research, pp. 201-221, 2013.

[26] P. Rezaie, K. Rezaie, S. Nazari-Shirkouhi, and M. R. J. Tajabadi, "Application of fuzzy multi-criteria decision making analysis for evaluating and selecting the best location for construction of underground dam," Acta Polytechnica Hungarica, vol. 10, no. 7, pp. 187-205, 2013.

[27] S. Kaur, Y. Singh, and N. Kaur, "Applications of Multi-criteria Decision Making in Software Engineering," International Journal of Advanced Computer Science and Applications, vol. 7, no. 7, pp. 472-477, 2016.

[28] R. B. de Santis, L. Golliat, and E. P. de Aguiar, "Multi-Criteria Supplier Selection Using Fuzzy Analytic Heirarchy Process: Case Study from a Brazilian Railway Operator," Brazilian Journal of Operations \& Production Management, vol. 14, pp. 428-437, 2017.

[29] S. Rouhani, A. Ashrafi, and S. Afshari, "Fuzzy DEMATEL model for evaluation criteria of business intelligence," in Proceedings of the 16th International Conference on Enterprise Information Systems, ICEIS 2014, pp. 456-463, Portugal, April 2014.

[30] A. J. Chaghooshi, A. Arab, and S. J. H. Dehshiri, "A fuzzy hybrid approach for project manager selection," Decision Science Letters, vol. 5, no. 3, pp. 447-460, 2016.

[31] S. N. Taati and A. Esmaili-Dooki, "A hybrid method of Fuzzy DEMATEL/AHP/VIKOR approach to rank and select the best hospital nurses of a Years: A case study," Journal of Applied Research on Industrial Engineering, vol. 4, no. 2, pp. 116-132, 2017. 
[32] M. B. Ayhan, "A fuzzy AHP approach for supplier selection problem: a case study in a gearmotor company," International Journal of Managing Value and Supply Chains, vol. 4, no. 3, pp. $11-23,2013$.

[33] A. K. Digalwar, A. Borade, and B. Metri, "A Fuzzy AHP Approach for Supplier Selection," Operations and Supply Chain Management: An International Journal, vol. 7, no. 2, pp. 46-53, 2014.

[34] T. E. Saputro and B. D. Rouyendegh (Babek Erdebilli), "A hybrid approach for selecting material handling equipment in a warehouse," International Journal of Management Science and Engineering Management, vol. 11, no. 1, pp. 34-48, 2016.

[35] R. Karim and C. L. Karmaker, "Machine Selection by AHP and TOPSIS Methods," American Journal of Industrial Engineering, vol. 4, no. 1, pp. 7-13, 2016.

[36] J. Thor, S. H. Ding, and S. Kamaruddin, "Comparison of Multi Criteria Decision Making Methods From The Maintenance Alternative Selection Perspective," The International Journal Of Engineering and Science, vol. 2, pp. 27-34, 2013.

[37] S. H. Ding and S. Kamaruddin, "Selection of Optimal Maintenance Policy by Using Fuzzy Multi Criteria Decision Making Method," in Proceedings of the 2012 International Conference on Industrial Engineering and Operations Management, Istanbul, Turkey, 2012.

[38] M. A. Ortíz, H. A. Felizzola, and S. N. Isaza, "A contrast between DEMATEL-ANP and ANP methods for six sigma project selection: A case study in healthcare industry," $B M C$ Medical Informatics and Decision Making, vol. 15, no. 3, 2015. 


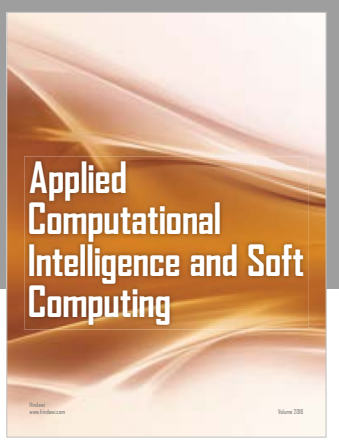

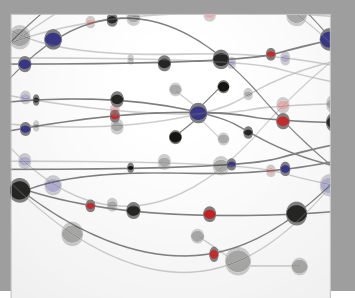

The Scientific World Journal
Submit your manuscripts at

Computing
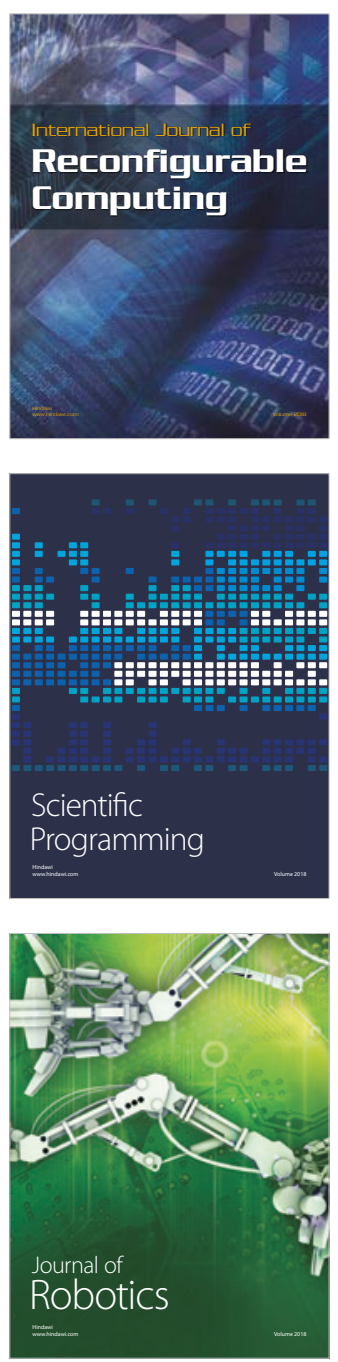

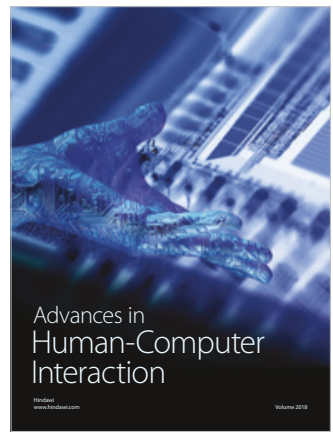

Human-Compute

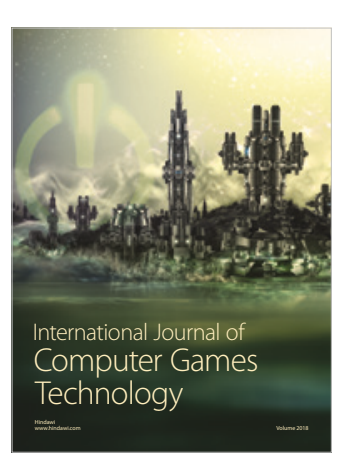

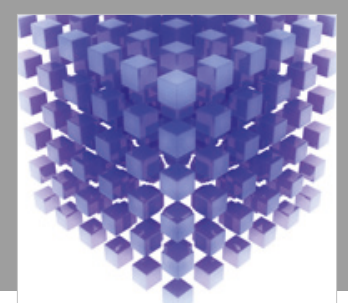

Mathematical Problems in Engineering

\section{Engincering}
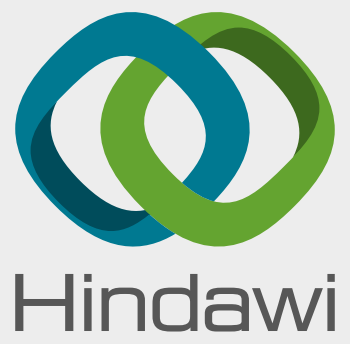

www.hindawi.com
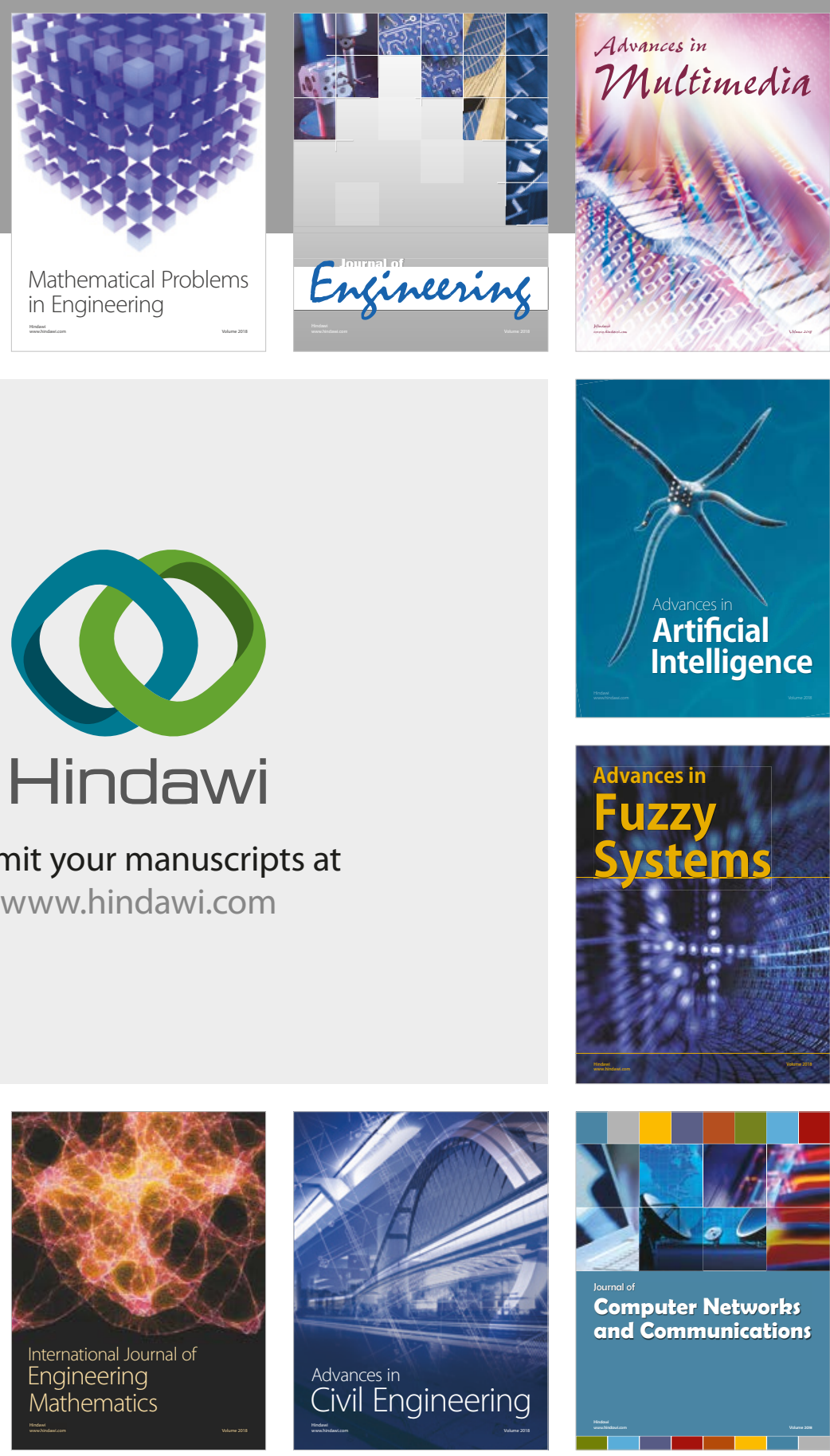

Computer Networks and Communications

Multimedia
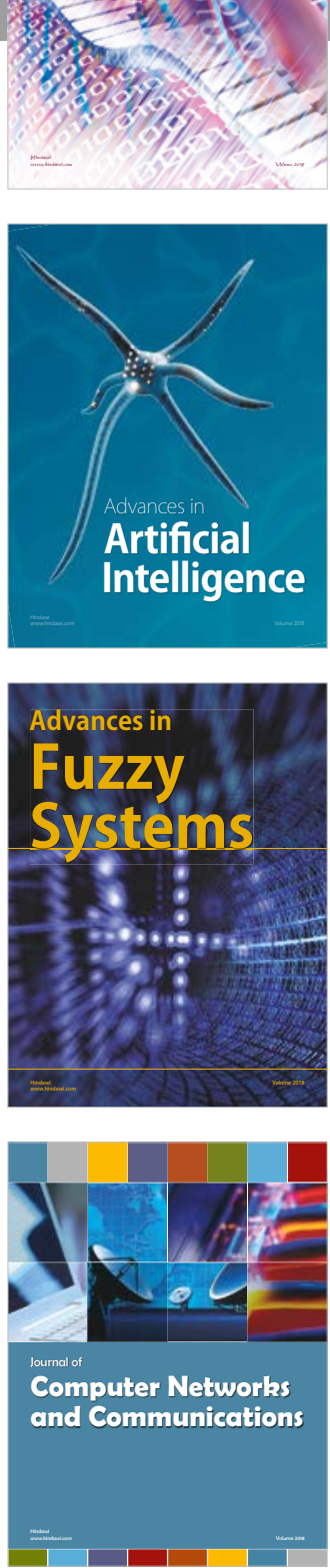

Advances in

Modelling \&

Simulation

in Engineering

interaction

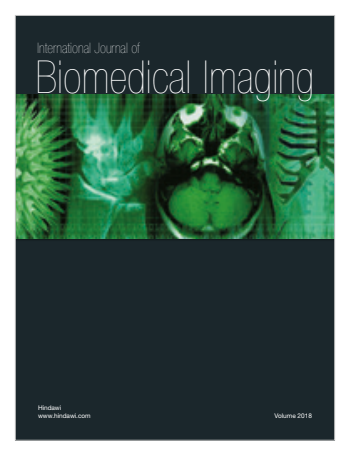

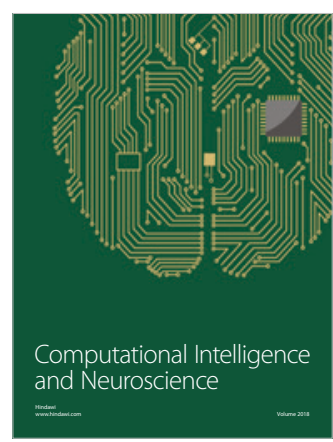

